\title{
A unified nomenclature for TATA box binding protein (TBP)-associated factors (TAFs) involved in RNA polymerase II transcription
}

\author{
Làszlò Tora ${ }^{1}$ \\ Institut de Génétique et de Biologie Moléculaire et Cellulaire, CNRS/INSERM/ULP, F-67404 ILLKIRCH Cedex, \\ CU de Strasbourg, France
}

Initiation of transcription by RNA polymerase II (Pol II) requires general transcription factors to assemble the Pol II pre-initiation complex (PIC) (Hampsey 1998). PIC assembly on both TATA-containing and TATA-less promoters can be nucleated by the general transcription factors TFIID or B-TFIID, which are comprised of the TATA-binding protein (TBP) and TBP-associated factors $\left(\mathrm{TAF}_{\mathrm{II}} \mathrm{S}\right)$ (Bell and Tora 1999; Albright and Tjian 2000). More than 10 years ago, the first $\mathrm{TAF}_{\mathrm{II}} \mathrm{S}$ were discovered in Drosophila and in human cells (Dynlacht et al. 1991; Tanese et al. 1991). These proteins were identified in biochemically stable complexes with TBP and named after their electrophoretic mobility in polyacrylamide gels. Subsequently, many $\mathrm{TAF}_{\mathrm{II}} \mathrm{s}$ from Saccharomyces cerevisiae, Schizosaccharomyces pombe, Caenorhabditis elegans, Drosophila melanogaster, and Homo sapiens have been identified. They are distinguished by a number, which indicates their apparent or predicted molecular weight. Cross-species comparisons show a strong sequence conservation of $\mathrm{TAF}_{\mathrm{II}} \mathrm{S}$ (Sanders and Weil 2000; Gangloff et al. 2001; Walker et al. 2001). Availability of genome sequences has accelerated the identification of $\mathrm{TAF}_{\mathrm{II}}$-orthologous and -related genes, resulting in uncertainty whether the gene in question encodes a genuine $\mathrm{TAF}_{\mathrm{II}}$. From a discussion initiated at the 2001 Cold Spring Harbor Laboratory meeting on Mechanisms of Eukaryotic Transcription it became clear that the current $\mathrm{TAF}_{\mathrm{II}}$ nomenclature is unsatisfactory. To clarify the relationship between orthologs and paralogs of $\mathrm{TAF}_{\mathrm{II}} \mathrm{S}$ and to avoid confusion stemming from molecular weights we propose a new unified nomenclature for the Pol II $\mathrm{TAF}_{\mathrm{II}} \mathrm{s}$. We believe that this will (1) aid cross-species comparisons in the literature and sequence databases, (2) facilitate interactions between various laboratories and scientists, (3) expedite literature searches, and (4) avoid confusion caused by similarity in the names of unrelated $\mathrm{TAF}_{\mathrm{II}} \mathrm{s}$.

${ }^{1}$ Corresponding author.

E-MAIL laszlo@igbmc.u-strasbg.fr; FAX 33-3-88-65-32-01.

Article and publication are at http://www.genesdev.org/cgi/doi/10.1101/ gad.976402.
The unified nomenclature is based on the following considerations:

1. It now appears evident from a comparison of Drosophila, human, and yeast TFIID that there is an essential or "core" set of TAFs that are conserved across many species. These 13 evolutionarily conserved TAFs (Sanders and Weil 2000) have been aligned with their orthologs from different species and designated TAF1 to TAF13 (see Table 1). After extensive discussions this nomenclature was chosen because of its simplicity and because it complies with guidelines endorsed by both the Saccharomyces Genome Database (SGD) and the human HUGO Gene Nomenclature Committees.

2. In the new nomenclature the suffix (II) to indicate TAFs involved in Pol II transcription will no longer be used. Discussions are currently underway in the research communities working with other respective TBP-containing complexes, that is, SL1/TIF-1B and TFIIIB, to also abandon the suffices (I) and (III) in the Pol I and Pol III literature.

3. If one organism harbors two genes or more belonging to the same TAF family and they have been shown to encode TBP-associated factors in biochemical experiments, these genes will be called, for example, TAF4 and TAF4b. At present, two bona fide paralogous TAF genes have been described belonging to the TAF4 family (human $\mathrm{TAF}_{\mathrm{II}} 135$ and $\left.\mathrm{TAF}_{\mathrm{II}} 105\right)$, the TAF5 family (S. pombe $\mathrm{TAF}_{\mathrm{II}} 72$ and $\left.\mathrm{TAF}_{\mathrm{II}} 73\right)$, and the TAF10 family $(D$. melanogaster $\mathrm{TAF}_{\mathrm{II}} 24$ and $\mathrm{TAF}_{\mathrm{II}} 16$ ) (see Table). This conforms to the SGD, which has used this exception previously (for example, for the ribosomal proteins).

The following scientists have endorsed the use of this nomenclature system: David Auble, Arnie Berk, Keith Blackwell, Martine Collart, Irwin Davidson, Rivka Dikstein, Alberto Ferrús, Jim Goodrich, Patrick Grant, Steve Hahn, Tetsuro Kokubo, Tony Kouzarides, Ruth Lovering (HUGO), James Manley, Ernest Martinez, Michael Meisterernst, Hiroshi Mitsuzawa, Yoshihiro Nakatani, Thomas Oelgeschläger, Frank Pugh, Joseph Reese, Robert Roeder, Georges-André Sentenac, Stephen Smale, Michel Strubin, Kevin Struhl, Naoko Tanese, Marc Timmers, Robert Tjian, Peter Verrijzer, Amy Walker, Edith Wang, David Wassarman, Tony Weil, Fred Winston, and Jerry Workman. 
Table 1. New Pol II TAF nomenclature including the corresponding known orthologs and paralogs

\begin{tabular}{|c|c|c|c|c|c|c|}
\hline \multirow[b]{2}{*}{ New name } & \multirow[b]{2}{*}{ H. sapiens (hs) } & \multirow[b]{2}{*}{ D. melanogaster (dm) } & \multicolumn{2}{|c|}{ C. elegans (ce) } & \multirow[b]{2}{*}{ S. cerevisiae (sc) } & \multirow[b]{2}{*}{ S. pombe (sp) } \\
\hline & & & previous name & new name & & \\
\hline TAF1 & $\mathrm{TAF}_{\mathrm{II}} 250$ & $\mathrm{TAF}_{\mathrm{II}} 230$ & taf-1 (W04A8.7) & taf-1 & Taf145/130 & $\mathrm{TAF}_{\mathrm{II}} 111$ \\
\hline TAF2 & $\mathrm{TAF}_{\mathrm{II}} 150$ & $\mathrm{TAF}_{\mathrm{II}} 150$ & taf-2 (Y37F11B.4) & taf-2 & Taf150 or TSM1 & (T38673) \\
\hline TAF3 & $\mathrm{TAF}_{\mathrm{II}} 140$ & $\mathrm{TAF}_{\text {II }} 155$ or BIP2 & (C11G6.1) & taf-3 & Taf47 & \\
\hline TAF4 & $\mathrm{TAF}_{\text {II }} 130 / 135$ & $\mathrm{TAF}_{\mathrm{II}} 110$ & taf-5 (R119.6) & taf-4 & Taf48 or MPT1 & (T50183) \\
\hline TAF4b & $\mathrm{TAF}_{\mathrm{II}} 105$ & & & & & \\
\hline TAF5 & $\mathrm{TAF}_{\mathrm{II}} 100$ & $\mathrm{TAF}_{\mathrm{II}} 80$ & taf-4 (F30F8.8) & taf-5 & Taf90 & $\mathrm{TAF}_{\mathrm{II}} 72$ \\
\hline TAF5b & & & & & & $\mathrm{TAF}_{\mathrm{II}} 73$ \\
\hline TAF5L & PAF65 $\beta$ & Cannonball & & & & \\
\hline TAF6 & $\mathrm{TAF}_{\mathrm{II}} 80$ & $\mathrm{TAF}_{\mathrm{II}} 60$ & taf-3.1 (W09B6.2) & taf-6.1 & Taf60 & (CAA20756) \\
\hline TAF6L & PAF65 $\alpha$ & (AAF52013) & taf-3.2 (Y37E11AL.8) & taf-6.2 & & \\
\hline TAF7 & $\mathrm{TAF}_{\mathrm{II}} 55$ & (AAF54162) & taf-8.1 (F54F7.1) & taf-7.1 & Taf67 & $\mathrm{TAF}_{\mathrm{II}} 62 / \mathrm{PTR} 6$ \\
\hline TAF7L & TAF2Q & & taf-8.2 (Y111B2A.16) & taf-7.2 & & \\
\hline TAF8 & (BAB71460) & Prodos & (ZK1320.12) & taf-8 & Taf65 & (T40895) \\
\hline TAF9 & $\mathrm{TAF}_{\mathrm{II}} 32 / 31$ & $\mathrm{TAF}_{\mathrm{II}} 40$ & taf-10 (T12D8.7) & taf-9 & Taf17 & (S62536) \\
\hline TAF9L & TAF $_{\text {II }} 31 \mathrm{~L}$ (AAG09711) & & & & & \\
\hline TAF10 & $\mathrm{TAF}_{\mathrm{II}} 30$ & $\mathrm{TAF}_{\text {II }} 24$ & taf-11 (К03B4.3) & taf-10 & Taf25 & (T39928) \\
\hline TAF10b & & $\mathrm{TAF}_{\mathrm{II}} 16$ & & & & \\
\hline TAF11 & $\mathrm{TAF}_{\mathrm{II}} 28$ & $\mathrm{TAF}_{\mathrm{II}} 30 \beta$ & taf-7.1 (F48D6.1) & taf-11.1 & Taf40 & (CAA93543) \\
\hline TAF11L & & & taf-7.2 (K10D3.3) & taf-11.2 & & \\
\hline TAF12 & $\mathrm{TAF}_{\mathrm{II}} 20 / 15$ & $\mathrm{TAF}_{\mathrm{II}} 30 \alpha$ & taf-9 (Y56A4.3) & taf-12 & Taf61/68 & (T37702) \\
\hline TAF13 & $\mathrm{TAF}_{\mathrm{II}} 18$ & (AAF53875) & taf-6 (C14A4.10) & taf-13 & Taf19 or FUN81 & (CAA19300) \\
\hline TAF14 & & & & & Taf30 & \\
\hline TAF15 & $\mathrm{TAF}_{\text {II }} 68$ & & & & & \\
\hline
\end{tabular}

B-TFIID

BTAF1 TAF $_{\mathrm{II}}$ 170/TAF-172 Hel89B $\quad$ (F15D4.1) btaf-1 $\quad$ Mot1

4. The species from which the TAF gene originates will be indicated by two letters (e.g., hsTAF1 for TAF 250 from H. sapiens).

5. Paralogous genes, which are found in the same organism to encode factors with homology to known Pol II TAFs, but which have not (yet) shown to be associated in stable complexes with TBP, will be called TAF-like genes, for example, TAF5L. This is the case for human PAF65 $\alpha$, PAF65 $\beta$, TAF2Q and their orthologs.

6. The C. elegans TAFs will use a nomenclature originally suggested by the Blackwell laboratory (Walker et al. 2001; i.e., taf-1 instead of TAF1, but they will keep the proposed numbering between 1 and 13. Furthermore, for reasons that are related to nomenclature recommendations in this organism the TAF-like genes will be called, for example, taf-6.2, taf-7.2, etc. For all other organisms we propose to follow the unified nomenclature.

7. For factors that show significant homology to either group ("essential TAF" or "TAF-like"), but have not been published or for which no biochemical characterization has been performed, accession numbers indicating their existence in the databases have been included in brackets. An empty box means that no orthologs or paralogs have been identified yet.

8. For specific TAFs, which do not seem to have a TAF ortholog in other species, TAF14 (S. cerevisiae
TAF30) and TAF15 (H. sapiens $\left.\mathrm{TAF}_{\mathrm{II}} 68\right)$ numbers have been assigned.

9. The $\mathrm{TAF}_{\text {II }} 170 / \mathrm{TAF} 172 / 89 \mathrm{~B}$ helicase/MOT1 genes present a special case. These proteins have been identified in biochemically stable complexes with TBP, which can support Pol II transcription in vitro. The $S$. cerevisae MOT1 gene was first identified genetically and its name has gained wide acceptance in the yeast community. Therefore, we suggest to maintain MOT1 for the yeast gene. For other organisms we propose to use BTAF1 to testify that the protein resides in a complex distinct from TFIID.

The proposed new nomenclature establishes a set of rules and a systematic way to name genes and proteins belonging to the TAF family of nuclear proteins playing a role in Pol II transcription regulation. The nomenclature is flexible enough to accommodate any species-specific subunits as they arise. Thus, the numbering of the essential core TAFs from 1 to 13 should make it easier to recall and to facilitate communication at all levels between researchers working inside and outside of the transcription field.

\section{References}

Albright, S.R. and Tjian, R. 2000. TAFs revisited: More data reveal new twists and confirm old ideas. Gene 242: 1-13. 
Bell, B. and Tora, L. 1999. Regulation of gene expression by multiple forms of TFIID and other novel TAFII-containing complexes. Exp. Cell Res. 246: 11-19.

Dynlacht, B.D., Hoey, T., and Tjian, R. 1991. Isolation of coactivators associated with the TATA-binding protein that mediate transcriptional activation. Cell 66: 563-576.

Gangloff, Y., Romier, C., Thuault, S., Werten, S., and Davidson, I. 2001. The histone fold is a key structural motif of transcription factor TFIID. Trends Biochem. Sci. 26: 250-257.

Hampsey, M. 1998. Molecular genetics of the RNA polymerase II general transcriptional machinery. Microbiol. Mol. Biol. Rev. 62: 465-503.

Sanders, S.L. and Weil, P.A. 2000. Identification of two novel TAF subunits of the yeast Saccharomyces cerevisiae TFIID complex. J. Biol. Chem. 275: 13895-13900.

Tanese, N., Pugh, B.F., and Tjian, R. 1991. Coactivators for a proline-rich activator purified from the multisubunit human TFIID complex. Genes \& Dev. 5: 2212-2224.

Walker, A.K., Rothman, J.H., Shi, Y., and Blackwell, T.K. 2001. Distinct requirements for C. elegans TAF(II)s in early embryonic transcription. EMBO J. 20: 5269-5279. 


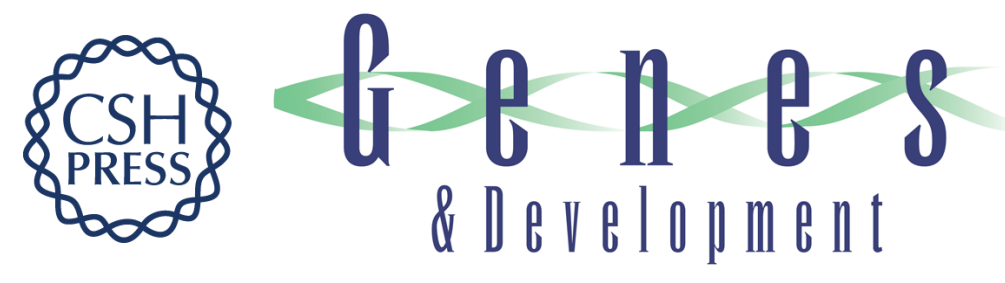

\title{
A unified nomenclature for TATA box binding protein (TBP)-associated factors (TAFs) involved in RNA polymerase II transcription
}

\author{
Làszlò Tora
}

Genes Dev. 2002, 16:

Access the most recent version at doi:10.1101/gad.976402

\section{References This article cites 8 articles, 4 of which can be accessed free at: http://genesdev.cshlp.org/content/16/6/673.full.html\#ref-list-1 \\ License}

Email Alerting
Service

Receive free email alerts when new articles cite this article - sign up in the box at the top right corner of the article or click here.

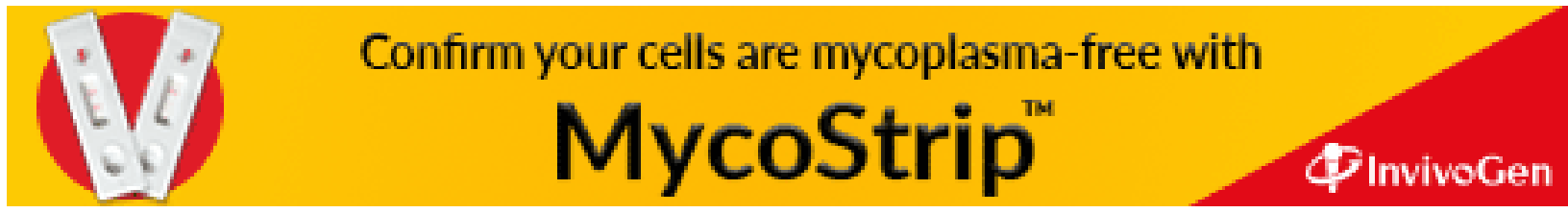

